\title{
Association between pre-pregnancy body weight and dietary pattern with large-for-gestational-age infants in gestational diabetes
}

\author{
Ana Munda', Marjanca Starčič Erjavec ${ }^{2}$, Katja Molan² $^{2}$ Jerneja Ambrožič Avguštin², Darja Žgur-Bertok ${ }^{2}$
} and Draženka Pongrac Barlovič ${ }^{3,4^{*}}$

\begin{abstract}
Background: Both obesity and gestational diabetes (GDM) are associated with adverse outcomes. Diet during pregnancy impacts weight gain and fetal growth. Therefore, we aimed to explore non-pharmacological treatment success depending on pre-pregnancy body weight and its association with large for gestational age (LGA) infants in women with GDM.

Methods: In our observational study we investigated 57 singleton pregnant women with GDM. All women received standard treatment, including healthy diet education and regular medical checkups. Data were collected through blood analysis, medical records and questionnaires assessing diet before conception and during pregnancy. Differences in dietary patterns were compared in normal weight and overweight/obese group using Mann-Whitney $U$, Wilcoxon Signed Rank Test or Kruskal-Wallis test, as appropriate. Logistic regression was used for prediction of LGA. p-value less than 0.05 was used for statistical significance.

Results: Preconceptionally, the Mann-Whitney $U$ test showed that the normal-weight group $(n=41)$ more frequently consumed fruits $(U=116.5, p<0.001)$, eggs $(U=189.5, p=0.02)$, cheese $(U=148.0, p=0.003)$ compared to the overweight/obese group $(n=16)$, that consumed more beef $(U=407.0, p=0.03)$ and low-calorie beverages $(U=397.0, p=0.05)$. During pregnancy both groups improved their diet, with no differences detected. Personality types differed only preconceptionally with regard to healthy diet. Excessive gestational weight gain did not significantly differ between body-weight groups (16.6\% vs. $23.1 \%)$, neither did the incidence of LGA infants (46.2\% vs. 43.8\%). Significant predictors of $L G A$ were paternal height $(\mathrm{OR}=1.12,95 \% \mathrm{Cl} 1.01-1.23)$, 3rd trimester HbA1C $(\mathrm{OR}=0.50,95 \% \mathrm{Cl}$ 0.26-0.97), unemployment $(\mathrm{OR}=4.80,95 \% \mathrm{Cl} 1.12-20.61)$ and diet improvement during pregnancy $(\mathrm{OR}=1.19,95 \% \mathrm{Cl} 1.02-1.39)$. After adjustment improvement in diet was no longer a significant predictor for LGA.

Conclusion: Even though dietary patterns of the participants significantly improved during pregnancy, LGA infants were born independently of pre-pregnancy weight or diet and despite good glycemic control. Further research is needed to explore social determinants of health and whether solutions outside the health sector could provide efficient means in preventing adverse pregnancy outcomes as well as improving metabolic health.
\end{abstract}

Keywords: Gestational diabetes, Obesity, Large-for-gestational-age (LGA), Personality

\footnotetext{
*Correspondence: drazenka.pongrac@gmail.com

${ }^{3}$ Department of Endocrinology, Diabetes and Metabolic Diseases,

University Medical Centre, Ljubljana, Slovenia

Full list of author information is available at the end of the article
}

(c) The Author(s) 2019. This article is distributed under the terms of the Creative Commons Attribution 4.0 International License (http://creativecommons.org/licenses/by/4.0/), which permits unrestricted use, distribution, and reproduction in any medium, provided you give appropriate credit to the original author(s) and the source, provide a link to the Creative Commons license, and indicate if changes were made. The Creative Commons Public Domain Dedication waiver (http://creativecommons.org/ publicdomain/zero/1.0/) applies to the data made available in this article, unless otherwise stated. 


\section{Background}

The epidemic of obesity and the growing incidence of diabetes are global public health issues. Obesity affects both sexes and all age groups. On a global scale, in $201640 \%$ of women and 39\% of men were overweight, while $11 \%$ of men and $15 \%$ of women were obese. Excessive weight and obesity are also increasing among children and adolescents with and 18\% prevalence of obesity among the 5 to 19 year age group [1]. Obesity is transmitted from generation to generation and represents an intergenerational vicious cycle [2]. As over $25 \%$ of women in their reproductive years prior to conception are overweight $(17 \%)$ or obese $(8 \%)$ [3], special attention should be paid to this phenomenon. Maternal obesity is associated with a higher risk of gestational diabetes mellitus (GDM) [4]. The incidence of GDM is growing worldwide [5] and in Europe the prevalence varies between 2 and 6\% [6]. Meta-analysis showed that the risk of developing GDM is two times higher among overweight women and four times higher among obese women, compared to pregnant women with normal weight [7]. GDM and obesity are associated with a number of risks for complications during pregnancy, delivery and later in life for mother and offspring $[8,9]$. The most common complication is birth of infants that are born large for gestational age (LGA), which prevalence is estimated at 18.3\% [10]. LGA infants have a higher risk of obesity, type 2 diabetes and cardiovascular diseases later in life [11]. Decreasing the incidence of LGA could therefore limit the obesity epidemic.

GDM treatment is usually focused on nutrition and/or physical activity with many times inconsistent results [12-14]. This may be because often glycemic control is overemphasized compared to the effects of obesity or gestational weight gain on negative pregnancy outcomes in everyday clinical practice. Moreover, personality traits and behaviors, which may lead to obesity, are often neglected $[15,16]$. Therefore, the main aim of our study was to assess whether the success of the treatment of gestational diabetes differs in women with obesity/overweight compared to normal weight women. Since the mainstay of the GDM treatment is dietary intervention, we sought to investigate whether changes in dietary pattern differs according to the BMI before pregnancy. In addition, we were interested whether personality types impact dietary change made by women with GDM. Since prevention of LGA infants is one of the main goals of the GDM treatment, our third aim was to explore whether change in diet pattern had an effect on the incidence of LGA infants.

\section{Methods and materials}

\section{Study design and sample}

Women treated for GDM in 2017 in an outpatient clinic at the University Medical Center Ljubljana were invited to participate in our longitudinal study. Fifty-seven consecutive women responded to our invitation and gave consent to participate. Diagnosis of GDM was based on a $3 \mathrm{~h} 75$ g glucose tolerance test (OGTT).

The participants received standard treatment in our outpatient clinic for pregnant women with GDM, which includes education on GDM and healthy diet. They were encouraged to keep a diet diary, monitor blood glucose levels and were regularly clinically examined with body weight measurement at each encounter at our clinic. Data were collected on three occasions: in the 2nd trimester, 3rd trimester and after delivery via an e-mail. In addition, data on pre-pregnancy body weight and weight at the time of delivery were collected from gynecological files. Excessive gestational weight gain was calculated based on IOM guidelines [17]. Fasting venous blood was sampled for the measurement of serum glucose, HbA1c, cholesterol and triglycerides using standard validated laboratory techniques.

\section{Measures}

Patients completed survey questionnaires regarding their lifestyle pre-conceptionally and during pregnancy. A short questionnaire that was developed by the Slovenian National Institute of Public Health was used as a measure of adherence to the principles of a healthy diet (Additional file 1: Table S1) [18]. Cronbach's alpha was acceptable for measurements performed pre-gravidally and during pregnancy $\left(\alpha_{1}=0.79, \alpha_{2}=0.70\right.$, respectfully). In addition, a frequency of food consumption list was used to assess how often participants consumed particular foods. Furthermore, we evaluated how often complex carbohydrates were chosen instead of simple ones. Single-item measure for assessing frequency of fried food consumption and number of daily consumed meals were also included. Additionally, demographic variables such as age, level of education, living environment, marital status, employment status (employed/unemployed), religious affiliation, mother's height and weight prior to conception, father's height and weight, as well as mother's and father's birth weight were collected.

Infant's birth weight and gestational age were extracted from birth records. We defined large for gestational age (LGA) as a birth weight at or above $90^{\text {th }}$ percentile for specific gestational age, based on a fetal weight equation [19].

The employed personality test [20] is an adaptation of the Persona personality test, that encompasses 34 items 
in pairs of opposite words. This test was used because it can be easily performed during routine clinical visits and can be rapidly analyzed on the spot by the nurse educators. Personality types determined by this test are based on two dimensions; the level of emotion (expressive or reserved) and the degree of power (directive or compliant). According to these two dimensions, the test divides people into four personality types; promoter (directive and expressive, interpersonal need is impact), facilitator (compliant and expressive, interpersonal need is membership), controller (directive and reserved, interpersonal need is achievement) and analyzer (compliant and reserved, interpersonal need is security).

\section{Statistical analyses}

Analyses were carried out using SPSS version 22. Most of the variables were not sufficient for the assumptions of parametric statistics, so we used non-parametric tests. Mann-Whitney U test was used to compare two independent groups (mainly normal weight and overweight/ obese group) and for comparing more than two independent groups Kruskal-Wallis test was conducted. Wilcoxon Signed Rank was used to assess differences from pre-pregnancy to state during pregnancy within each group.. Univariate and multivariate linear logistic regression was used for predicting the LGA. We used a standard way of reporting mean \pm SD. p-value of less than 0.05 was used as a limit of statistical significance.

\section{Results}

\section{Characteristics of the sample}

The final sample comprised 57 maternal-infant pairs. Table 1 presents characteristics of patients included in the study altogether and according to the BMI status. Participants age ranged from 22 to $42(31.4 \pm 5.1)$. There were 41 women with normal pre gravid body mass index (BMI), (age: $31.7 \pm 5.5$; BMI: $22.1 \pm 0.2)$ and 16 overweight $(n=9)$ or obese participants $(n=7)$. Their BMI ranged from 25.3 to 39.0 (age: $31.89 \pm 4.2$; BMI: $31.2 \pm 1.2$ ). BMI-based groups did not differ significantly on demographics (Table 2).

\section{Differences in eating patterns in women with GDM}

Before pregnancy the normal BMI group more frequently consumed fruits, eggs and cheese or cottage cheese than overweight and obese women (see Table 3) A Wilcoxon signed rank test indicated that all participants introduced positive changes in variables measuring nutrition, including an improvement in a healthy eating score $(Z=592.5, p<0.001)$, consuming complex carbohydrates more often $(Z=194 ; p=0.001)$, more
Table 1 Characteristics of patients included in the study altogether and according to the BMI status

\begin{tabular}{|c|c|c|c|}
\hline Demographic variables & $\begin{array}{l}\text { Normal weight } \\
(N=41) \\
M \pm S D \\
\mathrm{n}(\%)\end{array}$ & $\begin{array}{l}\text { Overweight } \\
\text { and obese } \\
(N=16) \\
M \pm S D \\
\mathrm{n}(\%)\end{array}$ & $\begin{array}{l}\text { Total } \\
(N=57) \\
M \pm S D \\
\mathrm{n}(\%)\end{array}$ \\
\hline \multicolumn{4}{|l|}{ Education } \\
\hline Secondary & $12(30.8)$ & $5(31.3)$ & $17(30.9)$ \\
\hline Vocational/BA & $11(28.2)$ & $6(37.5)$ & $17(30.9)$ \\
\hline $\mathrm{MA} / \mathrm{PhD}$ & $16(41.0)$ & $5(31.3)$ & $21(38.2)$ \\
\hline \multicolumn{4}{|l|}{ Living environment } \\
\hline Urban & $19(48.7)$ & $6(37.5)$ & $25(45.5)$ \\
\hline Suburban & $8(20.5)$ & $6(37.5)$ & $14(25.5)$ \\
\hline Rural & $12(30.8)$ & $4(25.0)$ & $16(29.1)$ \\
\hline \multicolumn{4}{|l|}{ Employment } \\
\hline Employed & $29(74.4)$ & $12(75.0)$ & $41(74.5)$ \\
\hline Unemployed & $10(25.6)$ & $4(25.0)$ & $14(25.5)$ \\
\hline \multicolumn{4}{|l|}{ Parity } \\
\hline 0 & $21(55.3)$ & $5(31.3)$ & $26(48.2)$ \\
\hline 1 & $14(36.8)$ & $7(43.8)$ & $21(38.9)$ \\
\hline 2 & $3(7.9)$ & $4(25.0)$ & $7(13.0)$ \\
\hline \multicolumn{4}{|l|}{ Marital status } \\
\hline Single & $1(2.6)$ & $0(0)$ & $1(1.8)$ \\
\hline Married & $19(48.7)$ & $10(62.5)$ & $29(52.7)$ \\
\hline Non-marital partnership & $19(48.7)$ & $6(37.5)$ & $25(45.5)$ \\
\hline Pregravid smokers & $6(15.4)$ & $4(25.0)$ & $10(18.2)$ \\
\hline \multicolumn{4}{|l|}{ Personality types } \\
\hline Promoter & $6(19.4)$ & $3(21.4)$ & $9(20.0)$ \\
\hline Facilitator & $18(58.1)$ & $8(57.1)$ & $26(57.8)$ \\
\hline Controller & $0(0)$ & $0(0)$ & $0(0)$ \\
\hline Analyzer & $7(22.6)$ & $3(21.4)$ & $10(22.2)$ \\
\hline $\mathrm{Hba1C}_{2 \text { ndtrimester }}(\%)$ & $4.96 \pm 0.06$ & $4.96 \pm .10$ & $4.96 \pm 0.29$ \\
\hline $\mathrm{HbA} 1 c_{3 r d}$ trimester $(\%)$ & $5.11 \pm 0.39$ & $5.23 \pm 0.15$ & $5.15 \pm 0.34$ \\
\hline Triglycerides (mmol/l) & $1.77 \pm 0.62$ & $1.97 \pm 0.55$ & $1.83 \pm 0.60$ \\
\hline
\end{tabular}

meals per day $(Z=344, p<0.001)$ and reduced frequency of fried food consumption $(Z=2.353, p=0.02)$. During pregnancy no differences were detected with regard to consumption of particular foods among BMI groups.

\section{Diet differences among personality types}

Personality types differed in lifestyle related variables only pre-conceptionally. They significantly contributed to differences on the score of regarding healthy diet principles pre-conception $\left(\chi^{2}(2)=9.290 ; p=0.01\right)$. Analyzers, with mean rank score 9.36 , followed the principles of a healthy diet to a lesser extent in comparison with facilitators, with mean rank score 22.00 , $p=0.009$ and promoters, with mean rank score 27.28, 


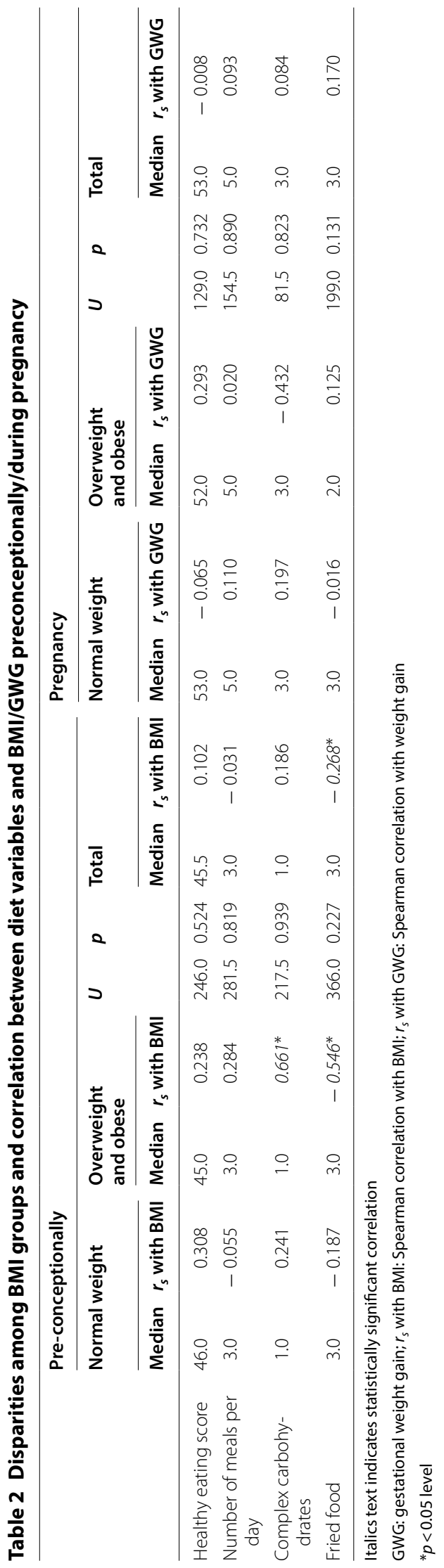




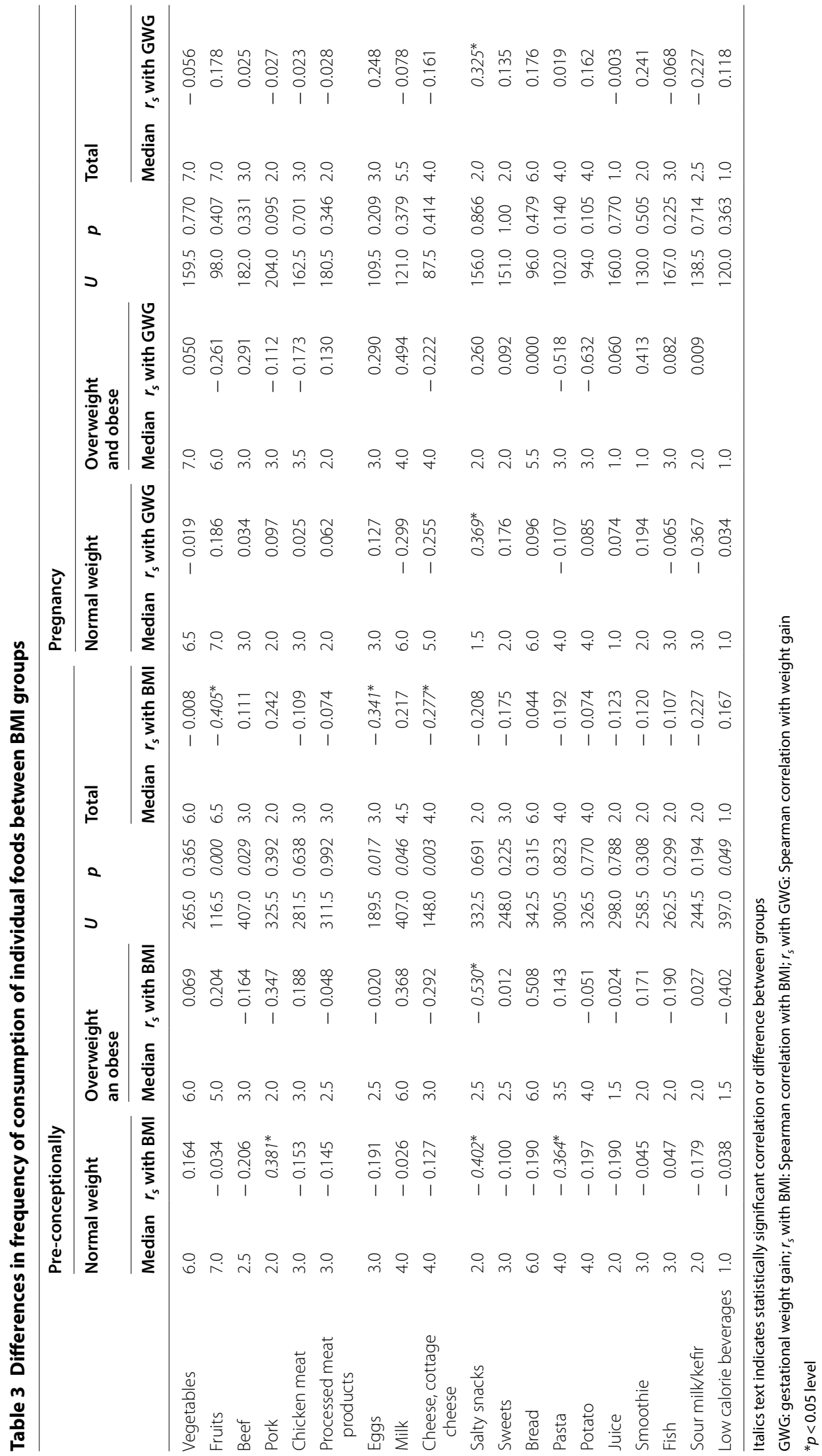


$p=0.04$. During pregnancy there were no differences among personality types.

\section{Diet-related factors, associated with LGA infants}

$45.5 \%$ of infant's birth weight was above 90th percentile, $14.5 \%$ weighted more than $4000 \mathrm{~g}$. LGA was equally distributed across BMI groups $(p=0.83)$ (see Additional file 1: Table S2). Gestational weight gain ranged from 0.5 to $22.9 \mathrm{~kg}(10.3 \pm 5.0)$ and was positively correlated with the infant's birth weight $(r=0.330, p=0.02)$, although no statistical significance was found after correction for gestational age.

A healthy eating score improvement during pregnancy was associated with LGA $(r=0.371, p=0.03)$ while fish consumption during pregnancy was negatively associated with LGA $(r=-0.444, p=0.008)$. Serum triglycerides were not significantly associated with LGA $(r=0.067$, $p=0.66$ ).

Some maternal and paternal anthropometric factors were associated with LGA. Maternal height was positively associated LGA in the normal weight group $(r=0.364, p=0.02)$, whereas paternal height $(r=0.316$, $p=0.02)$ and BMI $(r=0.577, p=0.01)$ were significantly correlated with LGA in the whole sample and in the overweight/obese group, respectively.

Statistically significant variables associated with LGA $(p<0.05)$ from a univariate logistic regression model are presented in Table 4. In the multivariate logistic regression model, difference in the healthy diet score was a statistically significant predictor of the LGA in the first step $(\mathrm{OR}=1.39$, 95\% CI 1.02-1.90). However, after adjustment for paternal height, employment status and glycated hemoglobin, improvement in diet was no longer a significant predictor for LGA (adjusted OR $=1.70,95 \%$ CI 0.80-3.60).

\section{Discussion}

Both, maternal obesity and GDM are risk factors, associated with obesity of the offspring as well as type 2 diabetes of the offspring and mother later in life. Therefore, optimizing treatment of pregnant women with GDM to avoid or reduce long and short term negative

Table 4 Univariate logistic regression for variables associated with LGA

\begin{tabular}{lll}
\hline & OR $[\mathbf{9 5 \%} \mathrm{Cl}]$ & $\boldsymbol{p}$ value \\
\hline Paternal height & $1.12[1.01,1.23]$ & 0.03 \\
Employment (unemployed) & $4.80[1.12,20.61]$ & 0.04 \\
Healthy eating score & $1.19[1.02,1.39]$ & 0.03 \\
HbA1C $_{\text {3rd trimester }}[0.1 \%]$ & $0.50[0.26,0.97]$ & 0.04 \\
\hline
\end{tabular}

outcomes is of the utmost importance. The majority of participants in our study showed improvement in dietary habits during pregnancy. We showed that preconception diet disparities among normal weight and overweight/obese groups and among different personality types disappeared during pregnancy. Women improved their dietary patterns, independently of obesity status or personality type, thereby confirming the success of education and non-pharmacological treatment of GDM. Excessive gestational weight gain did not significantly differ between the BMI groups; neither did the incidence of LGA infants.

Many potentially modifiable variables were included in our study, which could help us adjust education to vulnerable groups. Another strength was that findings are easily transferable to our everyday clinical work with patients, because of the standard care treatment participants received. The research was also subjected to some limitations. The main disadvantage is small number of participants included and inequality in the number of participants in each group. The sample may be too small to detect statistically significant differences between groups. Voluntary participation may also bias findings. Those that decided to participate could have had a stronger interest in the main topic of our research and could have been more willing as well as more motivated to change their lifestyles. Further, major issues regarding the validity of dietary recalls are related to how accurately individuals can recall what they ate [21]. With time, these recalls are even less trustful and rely more on semantic memory, which may be more subject to a social approval bias than specific memory of specific recalls [22]. Also, social desirability may affect validity [23].

Unexpectedly, disparities among BMI groups pre-conception regarding the healthy diet score were not found in this study. Both groups followed the healthy diet guidelines. In addition, a positive association between BMI and fried food consumption was expected [24]. However, a negative correlation was found, especially among overweight/obese women. This may have been due to assessment through self-report. Overweight and obese women may be hesitant to report socially less desirable behavior, which might be often attributed to them as a cause of their obesity. Dietary studies showed that individuals who exhibited social desirability characteristics are more prone to underreport energy and fat intake [23, 25, 26]. In addition, normal weight women may pay more attention to their diet before pregnancy, which could contribute to normal BMI and therefore greater accuracy of their report. Alternatively, normal weight women might care less about what they eat and pay more attention to quantity rather than quality of the food consumed. Of note, we do not have data on the amount of food consumed, 
which, together with psychical activity, definitely contribute to BMI.

In our study infrequent consumption of fruits, eggs and cheese at baseline contributed to higher BMI pre-conception. Compared to the normal weight group, overweight/ obese women more often consumed milk and beef before pregnancy. Our results on fruits and beef intake support the findings from other research groups [27-29]. On the other hand, the correlation between egg consumption and BMI was not universally found [30]. However, studies are not entirely comparable due to differences in the investigated populations. Moreover, existing data on the association between dairy products and BMI do not provide clear conclusions $[31,32]$. It would probably be reasonable to measure the contribution of different dairy products to $\mathrm{BMI}$ individually, especially in relation to the development of diabetes later in life [33].

With the personality test [20] we aimed at investigating possible psychological contributions to differences in nutritional habits and possibly indirectly to obesity and gestational weight gain. However, in our study personality types differed only in relation to the principles of healthy diet pre-conception. Women who were classified as analyzers achieved the lowest score and declared as a group who ate the least healthy. The healthiest diet pre-conception was significant for promoters. Individual personality traits and eating styles may play a role in the extent to which individuals adhere to dietary guidelines and could play a role in maintaining a healthy lifestyle after pregnancy. Healthy choices of foods recommended by dietary guidelines are promoted by conscientiousness [34]. Some features such as discipline, self-control or work orientation, characteristics of consciousness, are less typical for analyzers than facilitators or promoters. In our study, differences in diet regarding personality types during pregnancy were not detected. However, personality types were not equally represented, therefore, further validations are needed.

Gestational weight gain is a well-recognized risk factor for LGA [35], but in our study the association was not confirmed. This may be due for not measuring the quantity of individual foods. As well as we did not assess all possible (important) factors contributing to gestational weight gain. Nevertheless, the percentage of women that exceeded the recommended weight gain was smaller than in most other studies, possibly due to a good follow-up at gynecologists and diabetes care clinics $[36,37]$.

Despite the fact that only a minority of women exceeded the recommended gestational weight gain and that all exhibited good glycemic control, the prevalence of LGA newborns in our study was relatively high. Interventions could help to limit weight gain.
However, other studies also showed that their power to ameliorate effects on birth outcome is limited [38-40]. Obesity has been reported to increase the risk of LGA delivery [41], however, in our study the prevalence of LGA newborns was comparable among the two BMI groups. Interestingly, improvement in diet from preconception was a significant predictor for LGA. The reason may be that in women in whom accelerated fetal growth was observed during pregnancy, more intensive education and more contacts with the nurse educators was in place to improve their diet. On the other hand, it is also possible that these women just provided more socially desirable answers. This however, is less likely as these women also exhibited lower glycated hemoglobin values. Nevertheless, it is plausible that unmeasured genetic and epigenetic factors play a decisive role in the intrauterine growth regulation [42, 43].

Special attention must be paid to the high risk of occurrence of LGA among unemployed women. The link between social determinants of health and pregnancy outcomes deserves special attention in future research. Maternal education is positively associated with children's eating habits, and parental healthy eating habits may serve as mediators [44]. Therefore, awareness of the importance of a healthy lifestyle must be raised among more vulnerable groups with the aim of gaining healthier habits and introducing them into the family environment. With the aim of closing the gap, group peer sessions, where they could make new contacts and exchange experiences, could be introduced [45]. Furthermore, the assessment of different programs for reduction of obesity postpartum is still unanswered. Monitoring and guiding obese women not just during pregnancy, but also before and after pregnancy, would probably provide the best pathway to reduction of obesity in society long-term.

\section{Conclusion}

To sum up, in patients with GDM, diet improvement and tight glycemic control cannot completely prevent LGA infants. Instead, efforts to interrupt obesity cycle should focus more on social support and mental health, particularly among obese women, in whom clinical psychological assessment and support would be almost necessary.

\section{Supplementary information}

Supplementary information accompanies this paper at https://doi. org/10.1186/s13098-019-0463-5.

Additional file 1: Table S1. Questionnaire on eating behavior. Table S2. Anthropometric and pregnancy outcome data. 


\section{Abbreviations}

GDM: gestational diabetes mellitus; LGA: large for gestational age; OGTT: oral glucose tolerance test; BMI: body mass index; GWG: gestational weight gain; SD: standard deviation.

\section{Acknowledgements}

Acknowledgements to nurses educators Melita Cajhen, Dunja Verbič and other clinical staff at the Clinical Department of Endocrinology, Diabetes and Metabolic diseases for all the devoted help in this study.

AM joined this study thanks to an interdisciplinary program "Creative path to knowledge" supported by Slovenian Ministry of education, science and sport and the European Social Fund.

\section{Authors' contributions}

DPB, KM, MSE, DŽ-B and JAA participated in the design of the study. AM analyzed the data and wrote the paper. DPB participated in the analysis and interpretation of the data. DPB, KM, MSE, DŽ-B and JAA revised it for important intellectual improvement. All authors read and approved the final manuscript.

\section{Funding}

None.

\section{Availability of data and materials}

The datasets used and analysed during the current study are available from the corresponding author on reasonable request.

\section{Ethics approval and consent to participate}

The study was approved by the Slovenian Medical Ethics Committee, No. 0120-323/2016-2.

\section{Consent for publication}

Not applicable.

\section{Competing interests}

The authors declare that they have no competing interests.

\section{Author details}

${ }^{1}$ Department of Psychology, University of Ljubljana, Faculty of Arts, Ljubljana, Slovenia. ${ }^{2}$ Department of Biology, University of Ljubljana, Biotechnical Faculty, Ljubljana, Slovenia. ${ }^{3}$ Department of Endocrinology, Diabetes and Metabolic Diseases, University Medical Centre, Ljubljana, Slovenia. ${ }^{4}$ Faculty of Medicine, University of Ljubljana, Ljubljana, Slovenia.

Received: 29 May 2019 Accepted: 13 August 2019

Published online: 22 August 2019

\section{References}

1. World Health Organization (WHO). Obesity and overweight. 2018. https ://www.who.int/news-room/fact-sheets/detail/obesity-and-overweight. Accessed 9 Apr 2019.

2. Catalano PM. Obesity and pregnancy — the propagation of a viscous cycle? J Clin Endocrinol Metabol. 2003;88(8):3505-6.

3. Steblovnik L. Debelost kot dejavnik tveganja $v$ nosečnosti in pri porodu. In: Bokal Vrtačnik E, Vogler A, ur. Zbornik prispevkov: XII. Spominski sestanek akad. prof. dr. Lidije Andolšek-Jeras. Vpliv debelosti na žensko zdravje v reproduktivnem obdobju; 2017 Dec 8; Ljubljana, Slovenija. V Ljubljani: Slovensko društvo za reproduktivno medicino; 2017. p. 41-4.

4. Lucovnik M, Blickstein I, Verdenik I, Steblovnik L, Trojner Bregar A, Tul N. Impact of pre-gravid body mass index and body mass index change on preeclampsia and gestational diabetes in singleton and twin pregnancies. J Matern Fetal Neonatal Med. 2014;27(18):1901-4.

5. World Health Organization (WHO). Global report on diabetes. https:// apps.who.int/iris/bitstream/handle/10665/204871/9789241565257_eng. pdf?sequence=1. Accessed 7 Apr 2019.

6. Damm P, Houshmand-Oeregaard A, Kelstrup L, Lauenborg J, Mathiesen ER, Clausen TD. Gestational diabetes mellitus and long-term consequences for mother and offspring: a view from Denmark. Diabetologia. 2016:59(7):1396-9.
7. Chu SY, Callaghan WM, Kim SY, Schmid CH, Lau J, England LJ, et al. Maternal obesity and risk of gestational diabetes mellitus. Diabetes Care. 2007:30(8):2070-6.

8. Jensen DM, Damm P, Sorensen B, Molsted-Pedersen L, Westergaard JG, Ovesen P, et al. Pregnancy outcome and prepregnancy body mass index in 2459 glucose-tolerant Danish women. Am J Obstet Gynecol. 2003;189(1):239-44

9. Ovesen P, Rasmussen S, Kesmodel U. Effect of prepregnancy maternal overweight and obesity on pregnancy outcome. Obstet Gynecol. 2011;118(2):305-12

10. Gortazar L, Flores-Le Roux JA, Benaiges D, Sarsanedas E, Paya A, Mane $L$, et al. Trends in prevalence of gestational diabetes and perinatal outcomes in Catalonia, Spain, 2006 to 2015: the Diagestcat Study. Diabetes Metab Res Rev. 2006:2019:e3151.

11. Kaul P, Bowker SL, Savu A, Yeung RO, Donovan LE, Ryan EA. Association between maternal diabetes, being large for gestational age and breast-feeding on being overweight or obese in childhood. Diabetologia. 2019;62(2):249-58

12. Viana LV, Gross JL, Azavedo MJ. Dietary intervention in patients with gestational diabetes mellitus: a systematic trials on maternal and newborn outcomes. Diabetes Care. 2014;37(12):3345-55.

13. Ruifrok $A E$, van Poppel M, van Wely M, Rogozinska E, Khan KS, de Groot CJ, et al. Association between weight gain during pregnancy and pregnancy outcomes after dietary and lifestyle Interventions: a meta-analysis. Am J Perinatol. 2014;31(05):353-64.

14. Catalano P, deMouzon SH. Maternal obesity and metabolic risk to the offspring: why lifestyle interventions may have not achieved the desired outcomes. Int J Obes. 2015;39(4):642-9.

15. Provencher V, Begin C, Gagnon-Girourard MP. Personality traits in overweight and obese women: associations with $\mathrm{BMI}$ and eating behaviours. Eat Behav. 2008:9(3):294-302.

16. Gerlach G, Herpertz S, Loeber S. Personality traits and obesity: a systematic review. Obes Rev. 2015;16(1):32-63.

17. Institute of Medicine (IOM). Weight gain during pregnancy: reexamining the guidelines. Washington, DC: The National Academies Press; 2009. https://www.cbsnews.com/htdocs/pdf/052809_pregnancy.pdf. Accessed 19 Dec 2018

18. Ribič C. Zdrav krožnik: priporočila za zdravo prehranjevanje. Ljubljana: Inštitut za varovanje zdravja RS; 2009. http://www.fao.org/3/a-az910o.pdf. Accessed 21 Dec 2018.

19. Gardosi J, Chang A, Kalyan B, Sahota D, Symonds EM. Customised antenatal growth charts. Lancet. 1992;339(8788):283-7.

20. Golay A. Discover your personality to improve your communication skills. 2017. http://IIInutrition.com/mod_III/TOPIC39/m394.pdf. Accessed 20 Feb 2019.

21. Ochner CN, Conceicao EM, Gorlova O. The validity of nutritional assessment: current status. In: Hardy GT, editor. Encyclopedia of nutrition research. New York: Nova Science Publishers; 2011. p. 189-96.

22. Smith AF, Jobe JB, Mingay DJ. Retrieval from memory of dietary information. Appl Cogn Psychol. 1991;5:269-96.

23. Hebert J, Clemow L, Pbert L, Ockene IS, Ockene J. Social desirability bias in dietary self-report may compromise the validity of dietary intake measures. Int J Epidemiol. 1995;24(2):389-98.

24. Bowman SA, Vinyard BT. Fast food consumption of U.S. adults: impact on energy and nutrient intakes and overweight status. J Am Coll Nutr. 2004;23(2):163-8.

25. Horner NK, Patterson RE, Neuhouser ML, Lampe JW, Beresford SA, Prentice RL. Participant characteristics associated with errors in self-reported energy intake from the women's health initiative food-frequency questionnaire. Am J Clin Nutr. 2002;76(4):766-73.

26. Taren DL, Tobar M, Hill A, Howell W, Shisslak C, Bell I, Ritenbaugh C. The association of energy intake bias with psychological scores of women. Eur J Clin Nutr. 1999;53(7):570-8.

27. Rautiainen S, Wang L, Lee IM, Manson JE, Buring JE, Sesso HD. Higher intake of fruit, but not vegetables or fiber, at baseline is associated with lower risk of becoming overweight or obese in middle-aged and older women of normal BMI at baseline. J Nutr. 2015;145(5):960-8.

28. Boggs DA, Rosenberger $L$, Rodriguez-Bernal CL, Palmer JR. Long-term diet quality is associated with lower obesity risk in young African American women with normal BMI at baseline. J Nutr. 2013;143(10):1636-41. 
29. Rouhani MH, Salehi-Abargouei A, Surkan PJ, Azadbakht L. Is there a relationship between red or processed meat intake and obesity? A systematic review and meta-analysis of observations studies. Obes Rec. 2014;15(9):740-8.

30. Woo HW, Choi BY, Kim MK. Cross-sectional and longitudinal associations between egg consumption and metabolic syndrome in adults $\geq 40$ years old: the Yangpyeong cohort of the Korean Genome and Epidemiology Study (KoGES_Yangpyeong). PLoS ONE. 2016;11(1):e0147729.

31. Wang W, Wu Y, Zhang D. Association of dairy products consumption with risk of obesity in children and adults: a meta-analysis of mainly crosssectional studies. Ann Epidemiol. 2016;26(12):870-82.e2.

32. Schwingshackl L, Hoffmann G, Schwedhelm C, Kalle-Uhlmann T, Missbach B, Knuppel S, Boeing H. Consumption of dairy products in relation to changes in anthropometric variables in adult populations: a systematic review and meta-analysis of cohort studies. PLOS ONE. 2016;11(6):e0157461.

33. Aune $D$, Norat $T$, Romundstad $P$, Vatten $L$ J. Dairy products and the risk of type 2 diabetes: a systematic review and dose-response meta-analysis of cohort studies. Am J Clin Nutr. 2013;98(4):1066-83.

34. Keller C, Siegrist M. Does personality influence eating styles and good choices. Direct and indirect effects. Appetite. 2015;84:128-38.

35. Goldstein RF, Abell SK, Ranasinha S, Misso M, Boyle JA, Black MH, et al. Association of gestational weigh gain with maternal and infant outcomes. JAMA. 2017;317(21):2207-25

36. Bodnar LM, Siega-Riz AM, Simhan HN, Himes KP, Abrams B. Severe obesity, gestational weight gain, and adverse birth outcomes. Am J Clin Nutr. 2010;91(6):1642-8.

37. Olson CM, Strawderman MS. Modifiable behavioral factors in a biopsychosocial model predict inadequate and excessive gestational weight gain. J Am Diet Assoc. 2003;103(1):48-54.
38. Oteng-Ntim E, Varma R, Croker H, Poston L, Doyle P. Lifestyle interventions for overweight and obese pregnant women to improve pregnancy outcome: systematic review and meta-analysis. BMC Med. 2012;10:47.

39. Dodd JM, Grivell RM, Crowther CA, Robinskon JS. Antenatal interventions for overweight or obese pregnant women: a systematic review of randomized trials. BJORG. 2010;117(11):1316-26.

40. Dodd JM, Turnbull D, Deussen AR, Grivelll RM, Yelland LN, Wittert G, et al. Antenatal lifestyle advice for women who are overweight or obese: LIMIT randomized trial. BMJ. 2014. https://doi.org/10.1136/bmj.g1285.

41. Ehrenberg HM, Mercer BM, Catalano PM. The influence of obesity and diabetes on the prevalence of macrosomia. Am J Obstet Gynecol. 2004;191(3):946-8.

42. Kamana KC, Shakya S, Zhang H. Gestational diabetes mellitus and macrosomia: a literature review. Ann Nutr Metab. 2015;66(suppl2):14-20.

43. Januar V, Desoye G, Novakovic B, Cvitic S, Saffery R. Epigenetic regulation of human placental function and pregnancy outcome: considerations for casual inference. AJOG. 2015;213(4):S182-96.

44. van Ansem WJC, Schrijvers CTM, Rodenburg G, van de Mheen D. Maternal education level and children's healthy eating behavior: role of the home food environment. Cross-sectional results from the Dutch INPACT study. Int J Behav Nutr Phys Act. 2014;11:44-64.

45. Heisler M. Overview of peer support models to improve diabetes selfmanagement and clinical outcomes. Diabetes Spectr. 2007;20(4):214-21.

\section{Publisher's Note}

Springer Nature remains neutral with regard to jurisdictional claims in published maps and institutional affiliations.
Ready to submit your research? Choose BMC and benefit from:

- fast, convenient online submission

- thorough peer review by experienced researchers in your field

- rapid publication on acceptance

- support for research data, including large and complex data types

- gold Open Access which fosters wider collaboration and increased citations

- maximum visibility for your research: over $100 \mathrm{M}$ website views per year

At BMC, research is always in progress.

Learn more biomedcentral.com/submissions 